\title{
LEADERSHIP STYLE, ORGANIZATIONAL PERFORMANCE, AND CHANGE THROUGH THE LENS OF EMOTIONAL INTELLIGENCE
}

\author{
Marisela JIMÉNEZ \\ University of Phoenix, Tempe, Arizona, UNITED STATES \\ e-mail: mariseladj@email.phoenix.edu
}

\begin{abstract}
Transformational leadership style and emotional intelligence are aiding managers' performance. This study explained the influence that transformational style and emotional intelligence flexibility subscale have on organizational performance during change initiatives. Emotional intelligence and leadership theory represent the theoretical lens and framework in the research study. Emotional intelligence flexibility subscale was assessed with the Emotional Quotient Inventory 2.0 (EQi 2.0), and transformational style was assessed with the Multifactor Leadership Questionnaire (MLQ 5X). The study included a population of 180 managers from a nonprofit company in Texas, USA. Data collected were analyzed using multiple linear regression and Pearson correlational model to assess if a relationship existed between managers' emotional intelligence flexibility subscale and transformational style. The results showed a relationship between the emotional intelligence flexibility subscale and the transformational style. This research study may be beneficial to leaders in all industries undergoing organizational change to apply emotional intelligence flexibility subscale and transformational leadership style during the implementation of change initiatives.
\end{abstract}

Keywords: organizational performance, change initiatives, change, leadership, emotional intelligence, flexibility, management.

JEL: C80, D91, L23, L25, M10.

\section{Introduction}

Organizations' performance is desirable in all industries, particularly during change initiatives. Although research studies have been conducted to measure organizational performance using traditional variables involving innovation, return on investment, market penetration, and profit margins (Sethibe and Steyn, 2016), limited empirical data exist about unconventional variables to measure organizational performance. The Hartnell, Kinicki, Lambert, Fugate, and Doyle (2016) study addressing organizational performance included limited information about leadership effectiveness.

Other researchers' studies conducted during the past decade have included emotional intelligence and leadership styles as possible links to organizational performance (Avolio and Bass, 2004), yet none of these studies have addressed organizational performance and change initiatives through the lens of emotional intelligences, flexibility subscale, and the transformational leadership style. Doucet, Shao, Wang, and Oldham (2016) expounded on organiza- tional performance and observed that managers are concerned about employees' affective behavior because of the rapid change in the workplace.

The factors that have positively affected organizational performance include job satisfaction, psychological empowerment, and organizational citizenship (Sawitri, et al., 2016). There is awareness that managers' emotional intelligence plays a role in employees' organizational commitment; however, additional research is needed to understand how this behavior affects organizational performance (Sinha and $\mathrm{Ku}-$ mar, 2016).

\section{Problem}

The 21 st century organizational leaders, unlike previous centuries, are experiencing an upheaval and high degree of uncertainty because of forces comprising of global competition, rapid evolution of technology, increased need for competent human capital, government's regulatory business policies, and the shifting nature of the economy (Park and Kim, 2015; Dominguez, Galán-González and Barro- 
so, 2015). Emotional intelligence has become the focus of studies to explain why some individuals are more competent than others in addressing similar issues involving organizational change (Ljungholm, 2014).

Managers in companies of all size and industry type, often seem to have difficulty in distinguishing emotional intelligence responses of employees during the process of organizational change (Mahal, 2016; Patel and Kumar, 2016). The lack of understanding of the emotional intelligence construct may result in the organization's failure to improve earnings, stakeholders' investments, and potential sustainable growth (Suan, et al., 2015).

The purpose of the research study was to examine managers' emotional intelligence flexibility subscale and also to determine whether a relationship existed between the emotional intelligence flexibility subscale and the transformational leadership style. The sample for this study included participants in managerial positions from a nonprofit company located in the state of Texas in the United States.

\section{Research Question}

Measuring emotional intelligence flexibility subscale in managers poses challenges because of the complexity of variable differences in behavior and emotions.

To help examine emotional intelligence flexibility subscale of managers and transformational leadership style, the following research question was formulated:

RQ. To what extent is transformational leadership style predicted by manager's emotional intelligence flexibility subscale?

The following hypotheses were included in relation to the research question in this study:

$\mathrm{H}_{0} 1$ : Transformational leadership style is not predicted by manager's emotional intelligence flexibility subscale.

$\mathrm{H}_{\mathrm{a}} 1$ : Transformational leadership style is predicted by manager's emotional intelligence flexibility subscale?

\section{$4 \quad$ Literature Review}

In the present study, emotional intelligence and transformational leadership style were studied. The findings of this quantitative correlational study may contribute to the existing body of knowledge related to leadership theory and emotional intelligence construct in context of organizational performance during change initiatives.

Organizational change requires managers' cognitive and affective abilities to understand stakeholders' reactions (Mahal, 2016; Mayur, 2016). The findings of this study may help managers identify emotional intelligence skills and transformational leadership style as effective approaches to develop systematic best practices to implement during organizational change initiatives.

Managers in organizational settings are highly responsible for the performance of the organization, and when issues affecting the organization lead to a decline in profit and growth, managers at all levels are generally believed accountable (Hosie and Nankervis, 2016).

The factors that have positively affected organizational performance include job satisfaction, psychological empowerment, and organizational citizenship (Malik and Naeem, 2016). Leadership theory was reviewed, in context, to comprehend how managers can use emotional intelligence skills to influence organizational performance. Leadership competencies have been required in managers to manage in a constantly changing environment in both public and private organizations. Yahaya and Ebrahim (2016) examined leadership styles in context of organizational performance, asserting that transformational leadership exhibited a positive relationship with effective managers. Malik, Javed, and Hassan (2017) expressed that transformational leadership style has been used around the world to help manage organizational challenges.

The value of emotional intelligence depicts the evolution in management practice, often found useful in providing managers with new ways to manage organizations (Zhang, 2016). The transformational leadership style is effective in terms of motivating followers to perform based on internal drives (Bass, 1985). Historically, managers are expected to identi- 
fy effective solutions to address disruptions that threaten employees' performance (Sverdrup, Schei, and Tjølsen, 2017). In context of effective management, more than a century ago, Frederick W. Taylor, for example, developed the scientific management theory to help organizations increase productivity by strategically controlling workers' performance (Locke, 1982). For nearly 100 years, managers around the world have used Taylor's principles of scientific management theory to lead and make decisions (Kitana, 2016; Lauer, 2016).

The evolution of management and leadership theory advanced with new shifting paradigms was influenced by 20th century theorists, for example, Fayol $(1949,1955)$ contributed new knowledge by outlining managers' six functions:
1) forecasting,
2) planning,
3) organizing,
4) commanding,
5) coordinating, and
6) controlling.

These six principles are still widely used by organizational managers. Fayol and Taylor helped change the way organizations were managed by establishing business models that can be used in nearly every business. Mayo (1930) challenged existing management practices by introducing a sociological approach and promoted a humanistic perspective in which workers' affective responses were taken into consideration.

In a changing business environment, managers by using the transformational leadership style may often help inspire, motivate, and lead employees toward a clear vision of hope and goal achievement.

Researchers have theorized that low level of organizational performance was associated with employees' lack of:

- job satisfaction,

- empowerment, and

- organizational citizenship, including frequent employee turnover (Sawitri, et al., 2016).

Leadership and emotional intelligence theory, including praxis, are strategically required to achieve desired organizational output during the implementation of change initiatives.

\section{The purpose of method}

The purpose of this quantitative correlational study was to examine the degree and extent, or a lack thereof, of relationship between the transformational leadership style and managers' emotional intelligence flexibility subscale. The study was undertaken using individuals in managerial roles from a nonprofit company located in the state of Texas in the United States.

\section{$6 \quad$ Method and design}

A quantitative correlational study was selected for the present study to examine the possible relationship between the emotional intelligence flexibility subscale of managers and the transformational leadership style.

A correlational design was appropriate to incorporate with the quantitative method study because examining the possible correlation between the independent variable, emotional intelligence, and the dependent variable, leadership style represented the focal point of the study. The correlational design was useful in helping to confirm or disconfirm the research question and hypotheses.

\section{$7 \quad$ Setting, population, sample}

In this study, data were collected using survey questions consists of the Emotional Quotient Inventory 2.0 (EQi 2.0) and Multifactor Leadership Questionnaire (MLQ 5X) instruments. A sample size power analysis was conducted in $\mathrm{G}^{*}$ Power 3.1.7.

The power analysis was conducted on the multiple linear regression. In addition to $\mathrm{G}^{*}$ Power, a sample size power analysis based on population was conducted. The population sample size analysis examined the population size, level of confidence, and confidence interval to determine the required sample size for the study. 
Level of confidence refers to the level to which the research found contained significant confidence that the null hypothesis can be rejected in favor of the alternative hypothesis and is calculated as $1-\alpha$. With the value for $\alpha$ of .05 , the level of confidence is .95 or $95 \%$. The confidence interval refers to margin of error within the study. A conventional 5\% was used for the margin of error, allowing for the scores to have an error up to $5 \%$. Using a population of 180 , confidence level of .95 , and confidence interval of .05 , the required sample size is 125 .

Combined with the G*Power estimate, the sample size used from the study was aimed to be at least 85 , with a goal of at least 125 . For this study, the sample size included at least 125 individuals in a random selection from a sample frame of 180 participants occupying managerial roles from a nonprofit company located in the state of Texas in the United States.

\section{$8 \quad$ Materials and instruments}

The instrument to measure emotional intelligence in this study was the EQi 2.0 developed by Dr. Bar-On (1997) and improved by Stein and Book (2011). Permission to use the EQi 2.0 assessment resulted from a request made to Multi-Health Systems, Inc. The specific research plan included measuring emotional intelligence using the EQi 2.0 by assessing participants on the emotional intelligence flexibility subscale. The EQi 2.0 survey questions consist of brief and cohesive sentences that served to facilitate participants' understanding and quick response (see Appendix A).

Measuring the transformational leadership style necessitated using the MLQ 5X instrument. Permission to use the MLQ 5X instrument was granted from Mind Garden, Inc.

The assessment of participants for the transformational style consists of the following subscales: (a) idealized influence; (b) individualized consideration; (c) inspirational motivation, and (d) intellectual stimulation.

MLQ 5X survey questions consisted of comprehensive and short statements (see Appendix B).

\section{Quantitative: validity/reliability of the instruments}

Researchers have measured emotional intelligence using various instruments, including the Multifactor Emotional Intelligence Scale (MEIS), the EQi, the Emotional Competence Inventory (ECI), the MSCEIT, and its newest version, the MSCEIT V2.0, among other instruments that have evolved to improve the reliability and validity for measuring emotional intelligence.

For this study, the EQi 2.0 found favor after a careful perusal and selection of scientifically validated research instruments. The reliability and validity of the MLQ 5X instrument have been tested in more than 25 years of empirical research.

\section{Data collection and analysis procedure}

In accordance with ethical and legal requirements for data collection, Survey Monkey online tools platform was used to survey the participating individuals in this research study.

Using Survey Monkey online tools platform, an email link was sent to the sample frame. The email link included an informed consent statement with detailed information about the study's guidelines, instructions, and survey questions comprising of emotional intelligence flexibility subscale and the transformational leadership style; participants were asked to provide the following demographic information, but demographic data were not measured: (a) age; (b) gender, and; (c) level of education.

The data were collected electronically and subsequently analyzed. Statistics generated from the data analysis was used to interpret and explain the results obtained by analyzing the data.

The data were entered into SPSS version 20.0 for Windows. Descriptive statistics were considered to describe the transformational style. Multiple linear regression analyses were used to test the emotional intelligence flexibility subscale and the transformational style. Other statistical techniques, including Pearson correlation analysis, were used to complete the data analyses to strengthen the interpretation of the results obtained by analyzing the data. 
The data were rigorously analyzed to interpret reliability and validity of participants' responses and to examine if a correlation existed between the independent and dependent variables and their strength and degree, or a lack thereof.

\section{Results}

This quantitative correlational study was designed to examine managers' emotional intelligence flexibility subscale and the transformational leadership style. The total sampling frame consists of 180 individuals aged 18 years or older in full time managerial roles.

Contemporary managers in companies of all size and industry type seem to have difficulty in distinguishing emotional intelligence responses of employees during the process of organizational change, and irrespective of industry, managers' limited knowledge of how employees' emotional responses impact the implementation of change initiatives could possibly contribute to organizational decline. Quantitative correlational data were imperative to test hypotheses 1 and 2 in the research study:
RQ. To what extent is transformational leadership style predicted by managers' emotional intelligence flexibility subscale?

The following hypotheses were included in relation to the research question in this study:

$\mathrm{H}_{0} 1$ : Transformational leadership style is not predicted by manager's emotional intelligence flexibility subscale.

$\mathrm{H}_{\mathrm{a}}$ 1: Transformational leadership style is predicted by managers' emotional intelligence flexibility subscale?

The data that consisted of participants' responses to the EQi 2.0 assessment showed variations, indicating high indices in responses involving positive impressions. Questions concerning levels of competency were answered more favorably. Questions concerning low levels of competency were answered less favorably. Significant consensus was found in the flexibility subscale in which respondents answered mostly occasionally and sometimes indicated agreement regarding the lack of preference to undertake unpredictable change. Table 1 encompassed the 8item Emotional Quotient Inventory questions for the Flexibility Subscale and the number of participants' responses for each ranking category.

Table 1. Emotional Quotient Inventory 2.0 (EQi 2.0) Assessment Data for Flexibility Subscale, $\mathrm{N}=89$

(Source: Researcher's own work designed from the present research study findings)

\begin{tabular}{|c|c|c|c|c|c|}
\hline Answer & Never/Rarely & Occasionally & Sometimes & Often & $\begin{array}{c}\text { Always/ } \\
\text { Almost Always }\end{array}$ \\
\hline Question on EQi Survey & & & & & \\
\hline & 13 & 36 & 26 & 11 & 3 \\
\hline & 15 & 31 & 28 & 10 & 5 \\
\hline & 8 & 30 & 33 & 17 & 1 \\
\hline & 21 & 37 & 22 & 8 & 1 \\
\hline & 18 & 27 & 23 & 14 & 7 \\
\hline & 18 & 27 & 27 & 15 & 2 \\
\hline & 14 & 23 & 37 & 15 & 0 \\
\hline & 24 & 27 & 18 & 8 & 1 \\
\hline
\end{tabular}

The flexibility subscale involves adapting emotions, thoughts, and behaviors to unfamiliar, unpredictable, and dynamic circumstances or ideas. Participants' responses showed strong agreement to questions addressing the inability to welcome and adapt to change, indicating that most participants do not like 
unpredictable change and would rather choose more familiar situations. The flexibility skill is significant in context of organizational change. Resistance to change was found to contribute to emotional exhaustion, job dissatisfaction, and turnover intentions.

Fig. 1 illustrates the emotional intelligence Flexibility Subscale and the visual representation of participants' responses for each ranking category.

The transformation leadership style was assessed using the MLQ 5X consisting of the following sub- scales: (a) idealized influence behavior and idealized influence attributed; (b) inspirational motivation; (c) intellectual stimulation, and (d) individual consideration.

Table 2 comprised of the Multifactor Leadership Questionnaire 4-item questions for the Idealized Influence Behavior and the number of participants' responses for each ranking category.

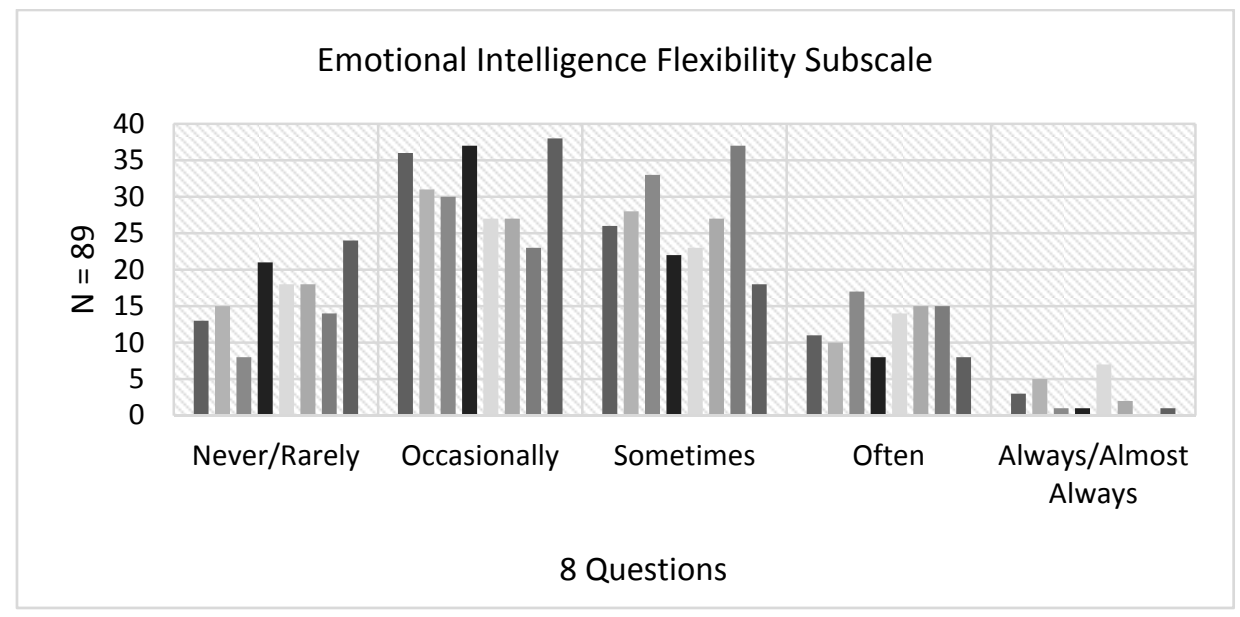

Figure 1. Emotional intelligence flexibility subscale responses

(Source: Researcher's own work designed from the present research study findings)

Table 2. Multifactor Leadership Questionnaire (MLQ 5X) Data

for Transformational Leadership Style (Idealized Influence Behavior) N=89

(Source: Researcher's own work designed from the present research study findings)

\begin{tabular}{|l|c|c|c|c|c|}
\hline Answer & Never/Rarely & Occasionally & Sometimes & Often & $\begin{array}{c}\text { Always/ } \\
\text { Almost Always }\end{array}$ \\
\hline Question on MLQ Survey & & & & & \\
\hline & 5 & 8 & 21 & 37 & 18 \\
\hline & 0 & 2 & 11 & 34 & 42 \\
\hline & 0 & 0 & 7 & 27 & 55 \\
\hline & 0 & 1 & 9 & 46 & 33 \\
\hline 4 Questions & \multicolumn{7}{l}{} \\
\hline
\end{tabular}

The idealized influence behavior subscale consists of transformational leaders using the idealized influence behavior style: transformational leaders use power over followers who view the leader in an idealized way (Bass and Avolio, 2004). Positive associ- ations were found between the idealized influence behavior and participants' emotional intelligence flexibility subscale. Participants' low idealized influence and low flexibility subscale, however, impact the performance. 
Fig. 2 displays the Transformational Leadership Style Idealized Influence (Behavior) Subscale and the visual representation of participants' responses for each ranking category.
The Table 3 included the Multifactor Leadership Questionnaire 4-item questions for Idealized Influence Attributed and the number of participants' response for each ranking category.

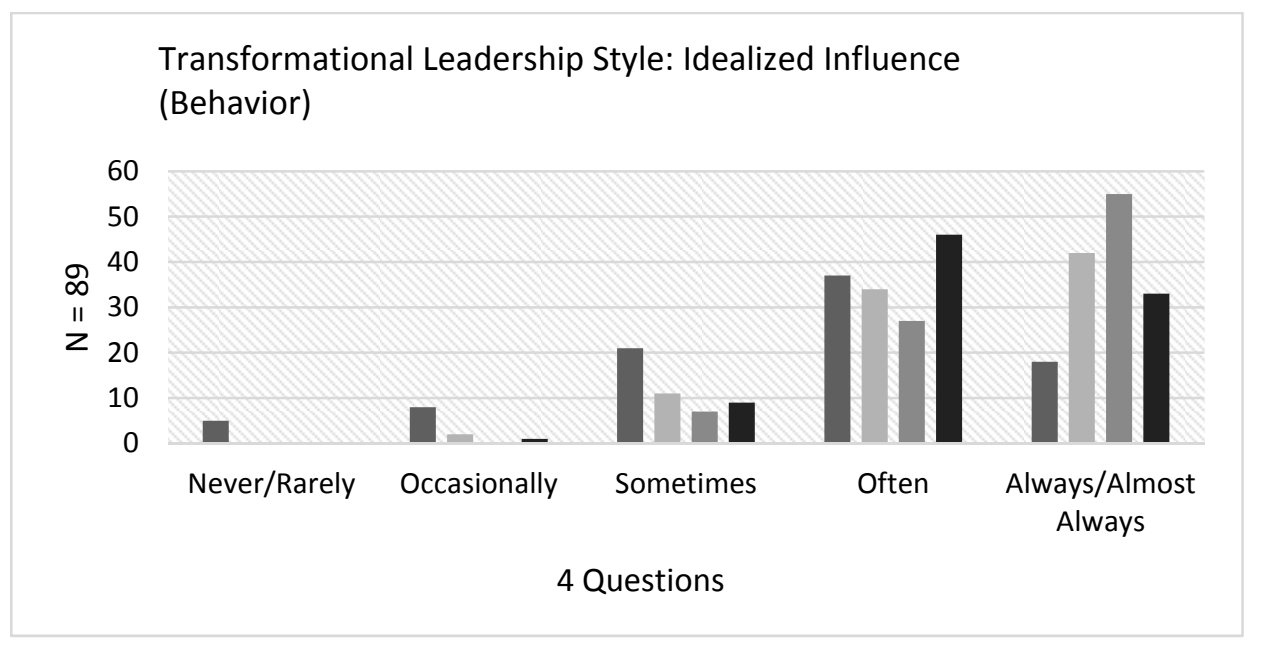

Figure 2. Idealized influence behavior responses

(Source: Researcher's own work designed from the present research study findings)

Table 3. Multifactor Leadership Questionnaire (MLQ 5X) Data

for Transformational Leadership Style (Idealized Influence Attributed), N $=89$

(Source: Researcher's own work designed from the present research study findings)

\begin{tabular}{|l|c|c|c|c|c|}
\hline Answer & Never/Rarely & Occasionally & Sometimes & Often & $\begin{array}{c}\text { Always/ } \\
\text { Almost Always }\end{array}$ \\
\hline Question on MLQ Survey & & & & & \\
\hline & 0 & 1 & 26 & 35 & 27 \\
\hline & 0 & 2 & 11 & 40 & 36 \\
\hline & 0 & 1 & 11 & 37 & 40 \\
\hline & 2 & 3 & 19 & 39 & 26 \\
\hline
\end{tabular}

The idealized influence attributed subscale consists of transformational leaders using the idealized influence attributed to arouse and inspire followers in the organization, with a vision of what can be accomplished through extra personal effort (Bass and Avolio, 2004). On the basis of the results obtained by analyzing the data, to accomplish organizational goals, it is noted that the transformational leadership style, idealized influence attributed, requires training to develop the skills to inspire followers. Participants with the lack of skills in inspiring followers lower the opportunities to achieve collective organizational results.

In Fig. 3, the Transformational Leadership Style includes the Idealized Influence (Attributed) Subscale and the visual representation of participants' responses for each ranking category

In Table 4, the Multifactor Leadership Questionnaire included the 4-item questions for Inspirational Motivation subscales and the number of participants' responses for each ranking category. 


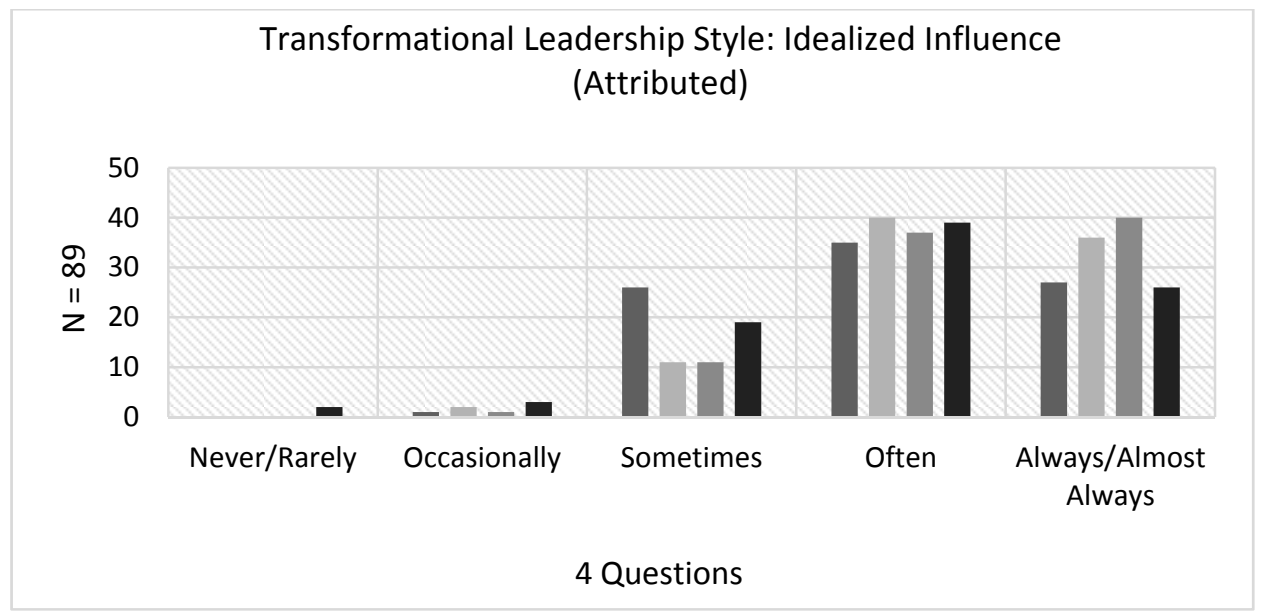

Figure 3. Idealized influence attributed responses

(Source: Researcher's own work designed from the present research study findings)

Table 4. Multifactor Leadership Questionnaire (MLQ 5X) Data

for Transformational Leadership Style (Inspirational Motivation), N $=89$

(Source: Researcher's own work designed from the present research study findings)

\begin{tabular}{|l|c|c|c|c|c|}
\hline Answer & Never/Rarely & Occasionally & Sometimes & Often & $\begin{array}{c}\text { Always/ } \\
\text { Almost Always }\end{array}$ \\
\hline Question on MLQ Survey & & & & & \\
\hline & 0 & 1 & 11 & 7 & 37 \\
\hline & 0 & 0 & 18 & 41 & 45 \\
\hline 4 Questions & 1 & 0 & 3 & 38 & 47 \\
\hline
\end{tabular}

The inspirational motivation subscale includes transformational leaders; these leaders use the inspirational motivation style to articulate, in simple ways, shared goals and mutual understanding of what is right and important (Bass and Avolio, 2004).

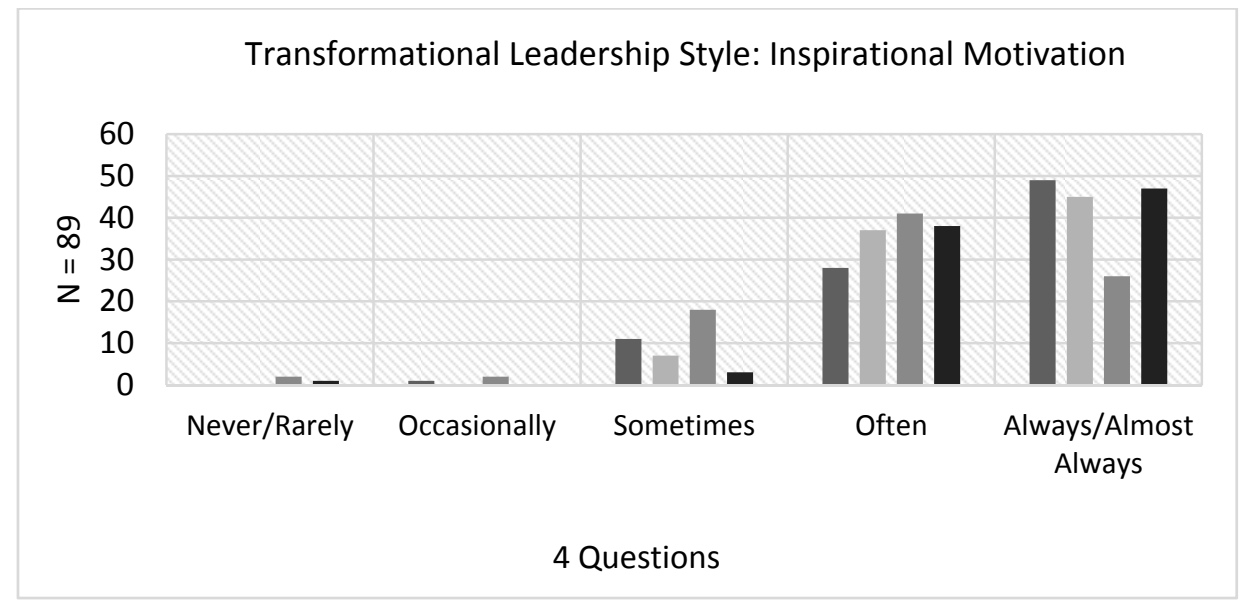

Figure 4. Inspirational motivation responses

(Source: Researcher's own work designed from the present research study findings) 
Participants' responses peaked toward high levels of competency; however, inspirational motivation is a skill, and unless participants receive training to develop such skill, they do not innately acquire inspirational motivation skills. The appropriate level of training is required to develop inspirational motivation skills to inspire and motivate followers, particularly in times of organizational change initiatives.
The Fig. 4 displays the Transformational Leadership Style Inspirational Motivation Subscale and the visual representation of participants' responses for each ranking category.

Table 5 included the Multifactor Leadership Questionnaire 4-item questions for Intellectual Stimulation subscales and the number of participants' responses for each ranking category.

Table 5. Multifactor Leadership Questionnaire (MLQ 5X) Data

for Transformational Leadership Style (Intellectual Stimulation), N = 89

(Source: Researcher's own work designed from the present research study findings)

\begin{tabular}{|l|c|c|c|c|c|}
\hline Answer & Never/Rarely & Occasionally & Sometimes & Often & $\begin{array}{c}\text { Always/ } \\
\text { Almost Always }\end{array}$ \\
\hline Question on MLQ Survey & & & & & \\
\hline & 1 & 1 & 15 & 42 & 30 \\
\hline & 0 & 1 & 13 & 54 & 21 \\
\hline & 1 & 4 & 15 & 41 & 30 \\
\hline & 0 & 1 & 10 & 48 & \\
\hline
\end{tabular}

The intellectual stimulation subscale consists of transformational leaders who use the intellectual stimulation style to help others to think about old problems in new ways (Bass and Avolio, 2004).

The data presented in Fig. 5 depicts scores of increased responses when assuming responsibility in proposing new alternatives in solving problems. The ability to solve problems requires skills using experience and a certain degree of education; there- fore, participants with low responses may necessitate to obtain training in developing the transformational leadership intellectual stimulation skill to help employees reach higher levels of organizational performance. Inferring from the results obtained by data analysis, most participants have not fully developed the intellectual stimulation skills; as a result, the success of the organization is diminished.

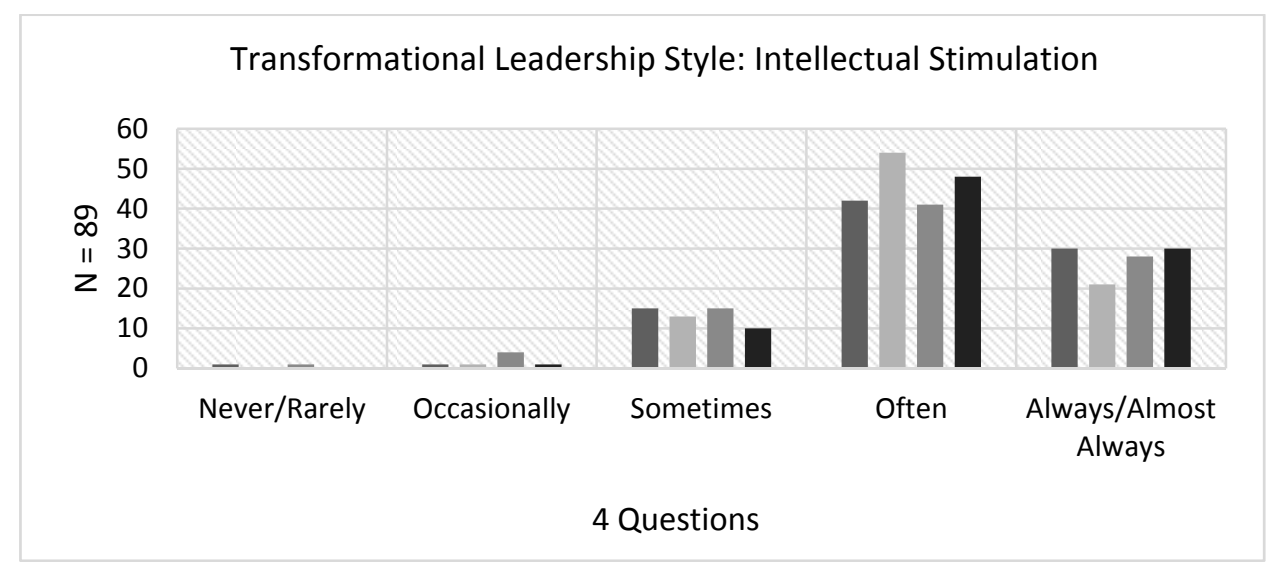

Figure 5. Intellectual stimulation responses

(Source: Researcher's own work designed from the present research study findings) 
Fig. 5 displays the Transformational Leadership Style Intellectual Stimulation Subscale and the visual representation of participants' responses for each ranking category.
Below, Table 6, comprised of the Multifactor Leadership Questionnaire 4-item questions for Individualized Consideration subscales and the number of participants' responses for each ranking category.

Table 6. Multifactor Leadership Questionnaire (MLQ 5X)

Data for Transformational Leadership Style (Individualized Consideration), N = 89

(Source: Researcher's own work designed from the present research study findings)

\begin{tabular}{|l|c|c|c|c|c|}
\hline \multirow{2}{*}{ Answer } & Never/Rarely & Occasionally & Sometimes & Often & $\begin{array}{c}\text { Always/ } \\
\text { Almost Always }\end{array}$ \\
\hline Question on MLQ Survey & & & & & \\
\hline & 2 & 2 & 10 & 32 & 43 \\
\hline & 2 & 0 & 7 & 38 & 42 \\
\hline & 2 & 0 & 9 & 37 & 41 \\
\hline & 2 & 2 & 7 & 46 & 34 \\
\hline
\end{tabular}

The individualized consideration subscale consists of transformational leaders who use the individualized consideration style to demonstrate understanding while focusing on others' concerns and developmental needs and treat individuals exceptionally (Bass and Avolio, 2004).

The Individualized consideration responses, as shown in Fig. 6, are higher in questions addressing levels of involvement and support towards other people needs. Though participants responded favora- bly toward often and always, having the ability to understand the affective responses of other people requires emotional intelligence (Bar-On, 1997); therefore, participants who seldom understand their own needs may be less effective in applying the individualized consideration skill.

Fig. 6 displays the Transformational Leadership Style Individualized Consideration Subscale and the visual representation of participants' responses for each ranking category.

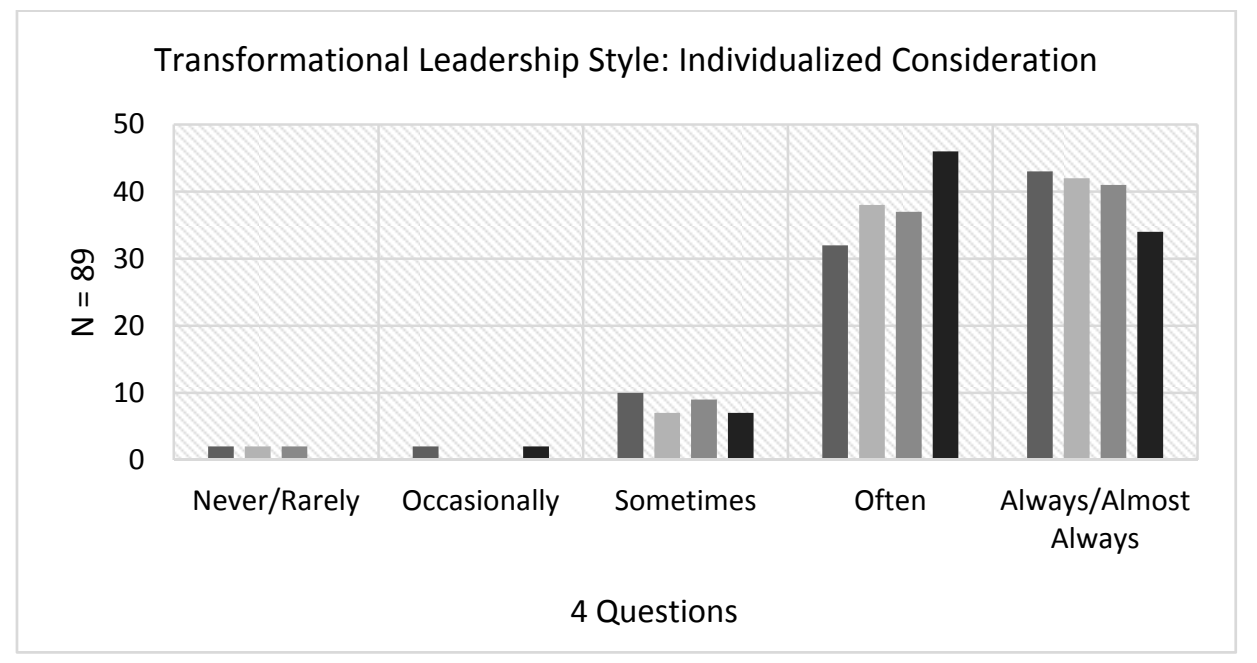

Figure 6. Individualized consideration responses

(Source: Researcher's own work designed from the present research study findings) 
The results of the linear regression were significant, $\mathrm{F}(1,87)=88.68, \mathrm{p}<.001$. The null hypothesis $\left(\mathrm{H}_{0} 1\right)$ could be rejected, suggesting that the linear regression did detect a significant relationship between emotional intelligence flexibility subscale and transformational leadership scores.

Emotional intelligence flexibility subscale was a significant predictor $(\mathrm{B}=.04, \mathrm{p}<.001)$ of transformational leadership style and accounted for 51\% of the variation in transformational leadership scores, which suggested that for a one unit increase in emotional intelligence flexibility subscale, transformational leadership scores increase by .04 units.

In addition to linear regression analyses, the following data analyses were conducted using Pearson correlation. The application of Pearson correlation served in analyzing the relationship between the subscales of transformational leadership style and emotional intelligence flexibility subscale.

Results from the Pearson correlational analysis indicated a significant association between emotional intelligence flexibility subscale and the subscales of transformational leadership style: idealized influence attributed $(\mathrm{r}=.55, \mathrm{p}<.001)$, idealized influence behavior $(r=.64, p<.001)$, inspirational motivation $(\mathrm{r}=.67, \mathrm{p}<.001)$, intellectual stimulation $(\mathrm{r}=.51$, $\mathrm{p}<.001)$, and individualized consideration $(\mathrm{r}=.60$, $\mathrm{p}<.001)$. In analyzing the data, the results indicated that emotional intelligence flexibility subscale accounted for a positive correlation involving the transformational leadership style. The significance consists of $F(1,87)=88.68, p<.001$, providing evidence to reject the null hypothesis.

\section{Conclusion}

The research question and hypotheses were necessary in addressing the current knowledge elucidated in the literature review. The results obtained by analyzing the data collected shed light about the relationship between emotional intelligence flexibility subscale and the transformational style.

A requirement of successful organizational performance involves managers' ability to understand the impact of change initiatives in employees' affective behavior. The role of the flexibility subscale is significant in addressing organizational performance because managers are expected to deliver optimum results. Therefore, the flexibility subscale merited examination in context of organizational performance and change initiatives.

The implications for resisting change, therefore, may compromise not only performance output but also interpersonal relationships, contributing to conflict and decline in overall organizational performance. Managers introducing change initiatives need to consider employees' affective responses to mitigate organizational negative outcomes. Thus, a manager who uses transformational leadership style with the ability to adapt emotions, thoughts, and behaviors to unpredictable change is identified to possess balanced emotional intelligence skills.

Fundamentally, an emotionally intelligent manager is best suited to manage organizational change initiatives while paying close attention to employees who may be experiencing similar affective reactions to change; neglecting to consider employees' emotional responses to change will further increase organizational decline.

\section{References}

[1] Asencio, H., Mujkic, E., 2016. Leadership Behaviors and Trust in Leaders: Evidence from the U.S. Federal Government. Public Administration Quarterly, 40(1), pp.156-179.

[2] Avolio, B.J., Bass, M.B., 2004. Multifactor Leadership Questionnaire Technical Manual (3rd ed.). Palo Alto: Mind Garden, Inc.

[3] Badri-Harun, A., Zainol, M.R., Amar, A., Shaari, Z.H., 2016. Emotional Intelligence as Mediator Between Leadership Styles and Leadership Effectiveness: A Theoretical Framework. International Review of Management and Marketing, 6(1).

[4] Bar-On, R., 1997. Bar-On Emotional Quotient Inventory (EQ-i): Technical Manual. Toronto: Multi-Health Systems.

[5] Bass, B.M., 1985. Leadership and Performance Beyond Expectations. New York: The Free Press.

[6] Dominguez CC, M., Galán-González, J.L., Barroso, C., 2015. Patterns of strategic change. 
Journal of Organizational Change Management, 28(3), pp.411-431.

[7] Doucet, L., Shao, B., Wang, L., Oldham, G.R., 2016. I know how you feel, but it does not always help. Journal of Service Management, 27(3), pp.320-338.

[8] Fayol, H., 1949, 1955. General and Industrial Managers. London: Sir Isaac Pitman \& Sons.

[9] Feng, C., Huang, X., Zhang, L., 2016. A multilevel study of transformational leadership, dual organizational change and innovative behavior in groups. Journal of Organizational Change Management, 29(6), pp.855-877.

[10] Hartnell, C.A., Kinicki, A.J., Lambert, L.S., Fugate, M., Doyle Corner, P., 2016. Do similarities or differences between CEO leadership and organizational culture have a more positive effect on firm performance? A test of competing predictions. Journal of Applied Psychology, 101(6), pp.846-861.

[11] Helpap, S., Bekmeier-Feuerhahn, S., 2016. Employees' Emotions in Change: Advancing the Sensemaking Approach. Journal of Organizational Change Management, 29(6), pp.903-916.

[12] Hosie, P., Nankervis, A., 2016. A multidimensional measure of managers' contextual and task performance. Personnel Review, 45(2), pp.419447.

[13] Kitana, A., 2016. Overview of the Managerial Thoughts and Theories from the History: Classical Management Theory to Modern Management Theory. Indian Journal of Management Science, 6(1), pp.16-21.

[14] Kranabetter, C., Niessen, C., 2016. How managers respond to exhausted employees. Journal of Personnel Psychology, 15(3), pp.106-115.

[15] Lam, C.F., Wan, W.H., Roussin, C.J., 2016. Going the Extra Mile and Feeling Energized: An Enrichment Perspective of Organizational Citizenship Behaviors. Journal of Applied Psychology, 101(3), pp.379-391.

[16] Lauer Schachter, H., 2016. Frederick Winslow Taylor, Henry Hallowell Farquhar, and the dilemma of relating management education to organizational practice. Journal of Management History, 22(2), pp.199-213.

[17] Li, Z., Gupta, B., Loon, M., Casimir, G., 2016. Combinative aspects of leadership style and emotional intelligence. Leadership \& Organization Development Journal, 37(1), pp.107-125.

[18] Ljungholm, D.P., 2014. Emotional intelligence in organizational behavior. Economics, Management and Financial Markets, 9(3), pp.128133.

[19] Locke, E.A., 1982. The Ideas of Frederick W. Taylor: An Evaluation. Academy of Managers Review, 7(1), pp.14-24.

[20] Jayakody, T., Gamage, P., 2015. Impact of the Emotional Intelligence on the Transformational Leadership Style and Leadership Effectiveness: Evidence from Sri Lankan National Universities. Journal of Strategic Human Resource Management, 4(1).

[21] Mączyński, J., Sułkowski, Ł., 2017. A seven nations study of leadership attributes. Polish Psychological Bulletin, 48(2), pp.307-314.

[22] Mahal, P.K., 2016. Influence of Emotional Intelligence on Employee Satisfaction: An Empirical Study of Banking Sector. Journal of Strategic Human Resource Management, 5(1).

[23] Malik, S.Z., Naeem, R., 2016. Organizational Virtuousness, Perceived Organizational Support and Organizational Citizenship Behavior: A Mediation Framework. Journal of Behavioural Sciences, 26(1), pp.113-129.

[24] Malik, W.U., Javed, M., Hassan, S.T., 2017. Influence of transformational leadership components on job satisfaction and organizational commitment. Pakistan Journal of Commerce and Social Sciences, 11(1), pp.146-165.

[25] Mayo, E., 1930. Changing methods in industry. Personnel Journal, ABI/INFORM Global, August 2010, 326.

[26] Mayur, S.J., 2016. Impact of cognitive competencies, emotional intelligence and locus of control on the performance of aspiring managers. Journal of Contemporary Research in Management, 11(1), pp.63-64.

[27] Myer, A.T., Thoroughgood, C.N., Mohammed, S., 2016. Complementary or competing climates? Examining the interactive effect of service and ethical climates on company-level financial performance. Journal of Applied Psychology, 101(8), pp.1178-1190.

[28] Park, S., Kim, E., 2015. Revisiting knowledge sharing from the organizational change perspec- 
tive. European Journal of Training and Development, 39(9), pp.769-797.

[29] Patel, K.R., Kumar, S., 2016. Emotional Intelligence and Managerial Effectiveness: A Comparative Study of Male and Female Managers. Indian Journal of Health and Wellbeing, 7(2), pp.244-247.

[30] Pearson, C.M., 2017. The smart way to respond to negative emotions at work. MIT Sloan Management Review, 58(3), pp.49-56.

[31] Sarangi, D., Pradhan, R.K., Jena, L.K., 2017. Emotional Intelligence, Organizational Role Stress and Job Satisfaction: Perspectives from Indian Public and Private Sector Organizations. Indian Journal of Positive Psychology, 8(4), pp.478-483.

[32] Saravo, B., Netzel, J., Kiesewetter, J., 2017. The need for strong clinical leaders -transformational and transactional leadership as a framework for resident leadership training. PLoS One, 12(8).

[33] Sawitri, Dyah, S.E., M.M., Suswati, Endang, S.E., M.S., Huda, Khasbulloh, S.E., M.M., 2016. The impact of job satisfaction, organization commitment, organization citizenship behavior (OCB) on employees' performance. International Journal of Organizational Innovation (Online), 9(2), pp.24-45.

[34] Sethibe, T., Steyn, R., 2016. Innovation and Organizational Performance: A Critical Review of the Instruments used to Measure Organizational Performance. The Southern African Journal of Entrepreneurship and Small Business Management, 8(1).

[35] Setiawan, B.M., Putrawan, I.M., Murni, S., Ghozali, I., 2016. Effect of Organizational Structure, Leadership and Trust on Job Performance of Employee: A Case Study on Employee at Universitas Ternama. International Review of Management and Marketing, 6(4).

[36] Sinha, C., Kumar, H., 2016. Relationship Between Emotional Intelligence, Work Attitude \&

\section{Appendix A}

\section{EQi 2.0 SURVEY QUESTIONS}

The EQi 2.0 provides you with an opportunity to describe yourself by indicating the frequency with
Outcomes: Examination of Indian MiddleManagerial Level Employees. Journal of Organizational Psychology, 16(1), pp.118-125.

[37] Smutny, P., Prochazka, J., Vaculik, M., 2016. The relationship between managerial skills and managerial effectiveness in managerial simulation game. Innovar, 26(62), pp.11-22.

[38] Stein, S.J., Book, H.E., 2011. The EQ Edge: Emotional Intelligence and Your Success (3rd ed.). Mississauga: John Wiley \& Sons Canada, Ltd.

[39] Suan, S.C.T., Anantharaman, R. N., Kin, D. T. Y., 2015. Emotional Intelligence and Organizational Performance: A Framework. Global Business and Management Research, 7(2), pp.37-43.

[40] Sverdrup, T.E., Schei, V., Tjølsen, Ø.A., 2017. Expecting the Unexpected: Using Team Charters to Handle Disruptions and Facilitate Team Performance. Group Dynamics: Theory, Research, and Practice, 21(1), pp.53-59.

[41] Vasudevan, H., Mahadi, N., 2017. Emotional Intelligence, Commitment and Climate in Organizations: Bridging Contribution and Practical Implication. Review of Integrative Business and Economics Research, 6, pp.202-216.

[42] Yahaya, R., Ebrahim, F., 2016. Leadership Styles and Organizational Commitment: Literature Review. The Journal of Management Development, 35(2), pp.190-216.

[43] Yanf, Z., Zhu, J., 2016. Charismatic Leadership Behavior and Leadership Effectiveness: The Moderating Role of Subordinates' Emotional Intelligence and the Mediating Role of Psychological Empowerment. Revista De Cercetare Si Interventie Sociala, 55, pp.158-184.

[44] Zhang, X., 2016. Co-evolution between institutional environments and organizational change.

[45] Journal of Organizational Change Management, 29(3), pp.381-403.

which you feel, think, or act in the way described by each statement. There are five response options for each statement:

Never/Rarely, Occasionally, Sometimes, Often, and Always/Almost Always. 
Read each statement and decide which one of the five response options best describes the frequency of your thoughts, feelings, or actions. Indicate your response choice by circling the appropriate number. If a statement does not apply to you, respond in such a way that will give the best indication of how you would possibly feel, think, or act. Although some of these statements may seem unclear or vague to you, choose the response option that seems to describe you best.
There are no "right" or "wrong" answers and no "good" or "bad" choices. Answer openly and honestly by indicating how you actually are, and not how you would like to be or how you would like to be seen. Although there is no time limit, work at a steady pace and make sure that you consider and try to respond to each statement. This assessment must be completed in a single session.

\begin{tabular}{|c|l|c|c|c|c|c|}
\hline \multicolumn{2}{|l|}{} & $\begin{array}{c}\text { Never/ } \\
\text { Rarely }\end{array}$ & $\begin{array}{c}\text { Occa- } \\
\text { sionally }\end{array}$ & $\begin{array}{c}\text { Some- } \\
\text { times }\end{array}$ & Often & $\begin{array}{c}\text { Always/ } \\
\text { Almost } \\
\text { Always }\end{array}$ \\
\hline 1 & I keep calm in difficult situations & 1 & 2 & 3 & 4 & 5 \\
\hline 2 & I make rash decisions when I'm emotional & 1 & 2 & 3 & 4 & 5 \\
\hline 3 & I back down even when I know I am right & 1 & 2 & 3 & 4 & 5 \\
\hline 4 & It's hard for me to make decisions on my own & 1 & 2 & 3 & 4 & 5 \\
\hline 5 & I interrupt when others are speaking & 1 & 2 & 3 & 4 & 5 \\
\hline 6 & It's difficult for me to change my opinion & 1 & 2 & 3 & 4 & 5 \\
\hline 7 & I say "no" when I need to & 1 & 2 & 3 & 4 & 5 \\
\hline
\end{tabular}

Copyright $(C 2012$ Multi-Health Systems Inc. All rights reserved

\section{Appendix B:}

\section{MLQ 5X SURVEY QUESTIONS}

This questionnaire is to describe your leadership style as you perceive it. Please answer all items on this answer sheet. If an item is irrelevant, or if you are unsure or do not know the answer, leave the answer blank.
Forty-five descriptive statements are listed on the following pages. Judge how frequently each statement fits you.The word "others" may mean your peers, clients, direct reports, supervisors, and/or all of these individuals.

Use the following rating scale:

\begin{tabular}{c|c|c|c|c} 
Not at all & Once in a while & Sometimes & Fairly often & $\begin{array}{c}\text { Frequently, } \\
\text { if not always }\end{array}$ \\
\hline 0 & 1 & 2 & 3 & 4
\end{tabular}

1. I provide others with assistance in exchange for their efforts

2. I re-examine critical assumptions to question whether they are appropriate

3. I fail to interfere until problems become serious

4. I focus attention on irregularities, mistakes, exceptions, and deviations from standards

5. I avoid getting involved when important issues arise $\begin{array}{lllll}0 & 1 & 2 & 3 & 4\end{array}$

6. I talk about my most important values and beliefs $\begin{array}{lllll}0 & 1 & 2 & 3 & 4\end{array}$

7. I am absent when needed. $\begin{array}{lllll}0 & 1 & 2 & 3 & 4\end{array}$

(C) 1995 Bruce Avolio and Bernard Bass. All Rights Reserved 